\title{
Evaluation of the Potential Anticancer Activity of Zamzam Water in Human Colon Cancer Cell Line
}

\author{
Huda A. Al Doghaither ${ }^{1, *}$, Ayat B. Al-Ghafari ${ }^{1}$, Sawsan A. Rahimulddin ${ }^{1}$, Shiekhah M. Al Zahrani ${ }^{1}$, \\ Abdulkader M. Shaikh Omar' ${ }^{2}$ Ulfat M. Omar ${ }^{1}$
}

\author{
${ }^{1}$ Department of Biochemistry, Faculty of Sciences, King Abdulaziz University, Kingdom of Saudi Arabia \\ ${ }^{2}$ Department of Biological Sciences, Faculty of Sciences, King Abdulaziz University, Kingdom of Saudi Arabia
}

Copyright@2016 by authors, all rights reserved. Authors agree that this article remains permanently open access under the terms of the Creative Commons Attribution License 4.0 International License

\begin{abstract}
Zamzam water (ZW) is a naturally hard alkaline type of water with unique physical and chemical properties that are different from any other water. The aim of the current work is to evaluate the potential anticancer activity of ZW against colon cancer. Human colon cancer HCT-116 and human skin fibroblast HSF cell lines were treated with two treatment conditions of $\mathrm{ZW}, \mathrm{Z} 1$ with adjusted $\mathrm{pH}$ to 7.4 and $\mathrm{Z2}$ without $\mathrm{pH}$ adjustment ( $\mathrm{pH} 8$ ). Cell viability was assessed using MTT and trypan blue dye exclusion assays. Cell cycle alterations and the type of cell death were investigated using flow cytometry technique. Cellular and mitochondrial reactive oxygen species (ROS) levels were quantified by H2DCFDA and MitoSOX assays, respectively. The results of the current study showed that both ZW treatments reduced cell viability of cancer cells. MTT assay showed a significant reduction in cell viability to $87 \%$ and $66 \%$, respectively, after treatment with $\mathrm{Z} 1$ and $\mathrm{Z} 2$ $(p \leq 0.0001)$. Cell death has occurred via apoptotic pathway under the two treatment conditions. The percentage of early apoptosis was $3 \%, 3.5 \%$ and $2.8 \%$ in control, $\mathrm{Z} 1$ and $\mathrm{Z} 2$ respectively. In the late apoptotic stage, there was a significant increase $(4.2 \%)$ only for $\mathrm{Z} 2$ treatment in comparison to the control $(p \leq 0.001)$. The cells were arrested in the G2/M phase of the cell cycle, and decreased in G1 phase after 24 hours of treatment with ZW. Only Z2 treatment, showed an increase in the production of both cytoplasmic and mitochondrial ROS. In conclusion, our results indicate, for the first time, that $\mathrm{ZW}$ induces apoptosis of human colon cancer HCT-116 cells, suggesting the potential anticancer effect of $\mathrm{ZW}$ against colon cancer.
\end{abstract}

Keywords Zamzam Water, HCT-116, Apoptosis, Antiproliferation, ROS

\section{Introduction}

Colon cancer is the second most prevalent cause of cancer death in men and women after lung cancer [1]. In Saudi Arabia, according to the latest statistical analysis report from the National Cancer Registry (NCR), colon cancer represents the first and the third most common malignancy in males and females, respectively [2]. Despite the evolution of scientific methods in understanding the biology of cancer and the discovery of new treatments, the mortality rate is still high. The reason that may explain the low rate of response to treatment is the resistance of cancer cells to radiotherapy and chemotherapy. Recently, standard chemotherapeutic agents are used as a supportive or as a main treatment of cancer. However, serious side effects have been reported for some anti-tumor chemotherapeutics. Nowadays, many studies are testing alternative and natural products to increase the response of the patients to the chemotherapeutic drugs or to overcome the toxic side effects of these drugs. Recently, scientists aim to develop oxygen-reduced water with high $\mathrm{pH}$ and mineral combination. A novel example is the electrolyzed-reduced water (ERW) which is widely used for its health benefits. ERW is characterized by high $\mathrm{pH}$ and lower oxidation potential [3]. It has been shown to possess anticancer properties such as inhibiting cell proliferation in lung A549 cancer cells [4], inhibiting tumor growth of B16 melanoma in tumor injected mice [5] and enhancing the mitochondrial apoptosis pathway in human promyelocytic leukemia cells (HL-60) [3].

Zamzam water ( $\mathrm{ZW})$ is a naturally hard carbonated type of water with unique physical and chemical properties that are different from any other water. The miraculous nature of this water is its continuous flow from Zamzam well since 2000 BC. Interestingly, the source of the water was mentioned in various religious books, including the Quran, the Bible and the Torah [6]. Millions of people drink ZW as a cure for many illnesses or for their religious belief. The chemical analysis showed that $\mathrm{ZW}$ contains 34 different elements. The concentrations of sodium $(\mathrm{Na})$, calcium $(\mathrm{Ca})$, chloride $(\mathrm{Cl})$, and magnesium $(\mathrm{Mg})$ are higher than natural water. Few traces of chromium $(\mathrm{Cr})$, manganese $(\mathrm{Mn})$, and titanium (Ti) are present in ZW [7-9]. Moreover, the amount of toxic 
elements including, cadmium $(\mathrm{Cd})$, lead $(\mathrm{Pb})$, arsenic ( $\mathrm{As})$, and selenium (Se), is below the level of danger of human consumption. Furthermore, this water has a higher $\mathrm{pH}$ value (7.9 -8) than the $\mathrm{pH}$ value of ordinary water $(\mathrm{pH} 6.5-7)$ [8]. However, previous studies demonstrated that certain doses of some toxic minerals such as selenium, arsenic, and lithium inhibited the proliferation of cancer cells [10-12]. Furthermore, numerous researchers have focused on the relationship of $\mathrm{pH}$ and cancer. It was proved that cancer cells thrive when they were exposed to low $\mathrm{pH}$ medium but cannot survive in alkaline medium [13-14].

The presence of some elements such as selenium, lithium and arsenate in addition to the high $\mathrm{pH}$ value of $\mathrm{ZW}$, prompted us to hypothesize that this water may have anticancer effects against cancer cells. Based on this, the aim of the current study attempts to evaluate the potential antiproliferative and cytotoxic effects of $\mathrm{ZW}$ in human colon cancer (HCT-116) cell line.

\section{Materials and Methods}

\subsection{Cell Lines}

HCT-116 cell line and normal skin fibroblasts cells (HSF) were obtained, respectively, from King Fahad Medical Research Center (KFMRC) and King Abdulaziz University Hospital (KAUH), King Abdulaziz University (KAU), Jeddah, Kingdom of Saudi Arabia (KSA).

\subsection{Preparation of Culture Media}

The DMEM medium (Hyclone, USA) was supplemented with $10 \%$ fetal bovine serum (FBS) (Hyclone, USA), 1\% L-glutamine (Sigma-Aldrich chemical Co, Poole, UK), $1 \%$ penicillin/streptomycin (Gibco, Canada), and 1\% non-essential amino acids (Gibco, Canada). The $\mathrm{pH}$ of the medium was adjusted to 7.4. The medium was sterilized by $0.22 \mu \mathrm{m}$ filter and used to culture both HCT-116 and HSF cells. After reaching the desired confluence at $70 \%$, the growth medium was removed and treatments of $\mathrm{ZW}$ were tested for 24 hours.

\subsection{Preparation of $\mathrm{ZW}$ Treatments}

ZW was obtained directly from Zamzam well, which is located in the holly mosque, Makkah, KSA. One large patch was stored in sterilized glass bottles at room temperature until it was used. In this research, ZW dissolved in PBS was referred to as the treatment. Two samples of $\mathrm{ZW}$ were prepared in PBS designated as Z1 and Z2. In sterilized glass bottle, a PBS tablet (Oxoid, Hampshire, UK) was dissolved in $800 \mathrm{ml}$ of $\mathrm{ZW}$ and the $\mathrm{pH}$ was either adjusted to 7.4 (Z1) or left with natural Zamzam alkalinity $\mathrm{pH}=8$ (Z2). HCT-116 cells cultured in PBS only were used as a negative control and designated as $(\mathrm{C})$.

\subsection{Morphological Changes}

An $8 \times 10^{5}$ cells $/ \mathrm{ml}$ of HCT-116 and HSF cells were seeded in $25 \mathrm{~cm}^{2}$ flasks. Then, the changes of cell morphology were photographed after 24 hours using a Nikon Eclipse microscope at magnification power of (10x) for both $\mathrm{Z} 1$ and $\mathrm{Z} 2$ treatments and were compared to the negative control (C).

\subsection{Determination of Cell Viability}

\subsubsection{MTT Assay}

The cytotoxic effect of ZW on HCT-116 and HSF cell lines were also studied by performing three independent experiments with MTT assay. A concentration of $1 \times 10^{4}$ cells/well were seeded in a 96 well tissue culture plate and were incubated for 24 hours at $37^{\circ} \mathrm{C}$ and $5 \% \mathrm{CO}_{2}$. Then, the culture medium was replaced with $200 \mu 1 \mathrm{Z1}$ or Z2 treatments or with $200 \mu 1$ PBS as (C). MTT assay was performed by adding $20 \mu \mathrm{l}$ of MTT dye (Sigma-Aldrich chemical Co, UK) and incubated for 2 hours at $37^{\circ} \mathrm{C}$ and $5 \% \mathrm{CO}_{2}$. After that, the precipitates were dissolved with $200 \mu 1$ of isopropyl alcohol (BDH, England) and the developed colour intensity was measured at $490 \mathrm{~nm}$ using a BioTek microplate reader.

\subsubsection{Tryban Blue Exclusion}

When HCT-116 and HSF cells were $60-70 \%$ confluent after 24 hours incubation, they were treated with Trypan blue dye $(0.2 \%)$ (Hyclone, USA) and counted using a Hemocytometer.

\subsection{Determination of Cell Death Type}

In order to detect early and late apoptosis in HCT-116 and HSF cell lines, $8 \times 10^{5}$ cells/ $\mathrm{ml}$ were seeded in $25 \mathrm{~cm}^{2}$ flasks and incubated until they were $70 \%$ confluent. After that, cells were incubated with Z1, Z2 and the control medium for 24 hours. Then, the assay was carried out according to the manufacture instructions using Beckman Coulter flow cytometer. Minimum 10,000 events were acquired in the gated regions. The emission wavelengths for cells labelled with Annexin V-FITC (Abcam, UK) and with propidium iodide (PI) (Sigma-Aldrich chemical Co, UK) were 520 and $620 \mathrm{~nm}$, respectively.

\subsection{Cell Cycle Analysis}

HCT-116 and HSF cells were seeded in $25 \mathrm{~cm}^{2}$ flasks at a concentration of $8 \times 10^{5}$ cells/ ml until they were $60-70 \%$ confluent. Then cells were treated with $\mathrm{Z1}$ and $\mathrm{Z} 2$ for 24 hours. Cells were trypsinized and pellets were washed twice with PBS and fixed with $1 \mathrm{ml}$ of ice-cold fixing buffer (70\% ethanol in PBS) and incubated at $4^{\circ} \mathrm{C}$ over night. After that, the cells were re-suspended in $500 \mu 1$ PBS followed by $5 \mu 1$ of $5 \mathrm{mM}$ RNase (Abcam, UK) and were incubated for 30 minutes at $37^{\circ} \mathrm{C}$. Then $5 \mu 1$ of PI $(1 \mathrm{mg} / \mathrm{ml})$ was added and cells were analyzed by BD FACSCalibur flow cytometer. At 
least, 10,000 events were acquired in the list mode using an emission wavelength of $620 \mathrm{~nm}$.

\subsection{Measurement of Cellular Reactive Oxygen Species (ROS)}

Cellular ROS level in HCT-116 was measured using the Di-hydrodichlorofluorescein diacetate (H2-DCFDA) dye (Invitrogen, Paisley, UK) assay. The $8 \times 10^{5}$ cells were seeded in $25 \mathrm{~cm}^{2}$ flasks and treated with $\mathrm{Z} 1$ and $\mathrm{Z} 2$ for 24 hours. Then, $5 \mu$ l of DCFDA was added to cells and incubated in the dark (to reduce the susceptibility of photo-oxidation that might occur) for 30 minutes at $37^{\circ} \mathrm{C}$ and $5 \% \mathrm{CO}_{2}$. Using BioTek Fluorescence microplate reader, the DCF fluorescence was read at excitation wavelength of $485 \mathrm{~nm}$ and at emission wavelength of $528 \mathrm{~nm}$.

\subsection{Measurement of Mitochondrial Reactive Oxygen Species (mtROS)}

Mitosox red dye (Invitrogen, Paisley, UK) assay was used to detect the superoxide levels in HCT-116 cell line treated with $\mathrm{Z} 1$ and $\mathrm{Z} 2$. The level of superoxide in cells was measured by BioTek fluorescence microplate reader according to the manufacture instructions. The Red fluorescence was read at excitation wavelength of $530 \mathrm{~nm}$ and at emission wavelength of $590 \mathrm{~nm}$.

\subsection{Statistical Analysis}

All obtained data were statistically analyzed by Graph Pad Prism software version 6. All experiments were performed for at least three times to insure reproducibility of results. The significant differences were evaluated using $p$-values calculated by one-way analysis of variance (ANOVA) followed by Bonferroni's test correction. The cut-off level of statistical significance was $p<0.05$.

\section{Results}

\subsection{Morphological Changes}

The high alkaline medium treatment (Z2) showed more obvious changes in the cell membrane of HCT-116 cells than the adjusted $\mathrm{pH}$ treatment (Z1), as shown in Fig $1 \mathrm{~A} \& \mathbf{~ 1 B}$. In contrast, the same treatments had no observable antiproliferative effect on HSF and appeared intact when compared to the control.

\section{A) HCT-116}
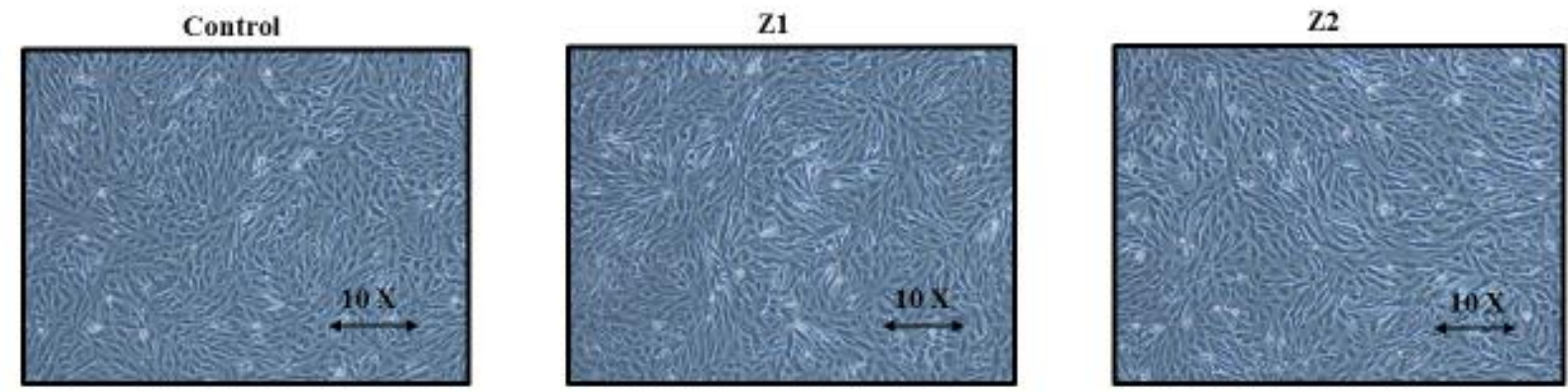

B) HSF


Figure 1. The effect of ZW treatments on the morphology of HCT-116 and HSF cells. A) HCT-116 cells incubated for 24 hours with Z1 and Z2 compared to the control. B) HSF cells treated with, Z1 and Z2 for 24 hours compared to the control. 


\subsection{Determination of Cell Viability}

\subsubsection{MTT Assay}

The MTT assay performed on HCT-116 cell line showed a highly significant reduction in cell viability to $87 \%$ and $66 \%$ after treatment with $\mathrm{Z} 1$ and $\mathrm{Z} 2$, respectively compared to control untreated HCT-116 cells ( $p<0.0001)$ (Fig 2A). Interestingly, no significant difference on the viability of the HSF cells was observed under the same ZW treatments (the cell viability for HSF cells was $95.02 \%$ and $97.9 \%$ at $\mathrm{Z1}$ and $\mathrm{Z} 2$, respectively).

\subsubsection{Trypan blue Exclusion}

Trypan blue cell count was used to confirm the effect of Zamzam treatments on cell viability. In agreement with MTT assay results, cell viability of HCT-116 was significantly reduced to $78 \%$ and $49 \%$, respectively (Fig 2B), with no significant effect on the cell viability of HSF cells.

\section{A) MTT}

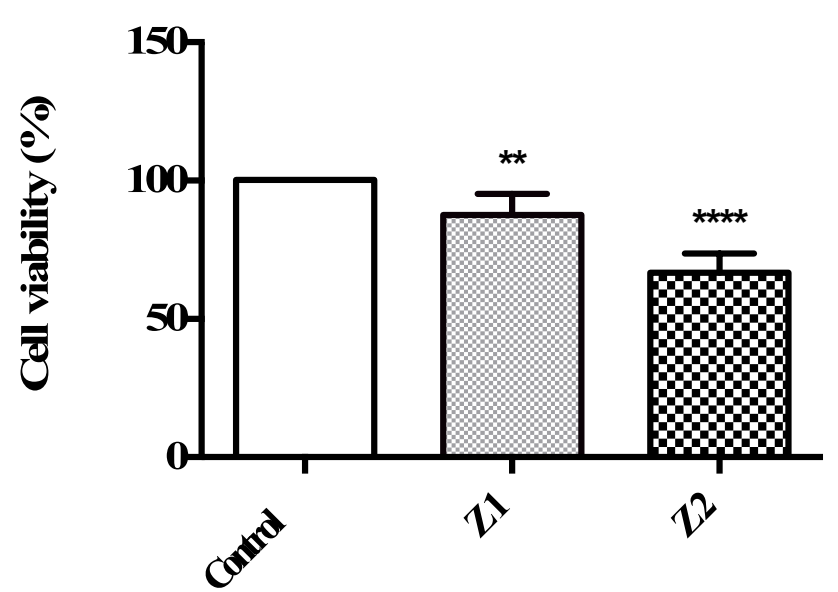

\subsection{Apoptosis in HCT-116 Cells}

Programmed cell death mechanism was significantly induced in HCT-116 treated with ZW compared with the untreated control. The percentage of cells at early apoptotic stage was $3 \%, 3.5 \%$ and $2.8 \%$ in control vs. $\mathrm{Z} 1$ and $\mathrm{Z} 2$ respectively. On the other hand, in the late apoptotic stage, no significant rise was observed between control $2.6 \%$ and Z1 $2.6 \%$, while there was a significant increase $4.2 \%$ for Z2 in comparison to the control $(p \leq 0.001)$. Both treatments showed no significant effect in cell necrosis. The percentage of necrosis in HCT-116 cells was $0.45 \%, 0.41 \%$ and $0.36 \%$ $(p>0.05)$ in control untreated cells, Z1 and Z2, respectively (Fig 3A). For normal HSF cells, $\mathrm{Z1}$ and $\mathrm{Z} 2$ showed no significant changes $(p>0.05)$ in all apoptotic stages and necrosis (Fig 3B).

\section{B) Trypan blue}

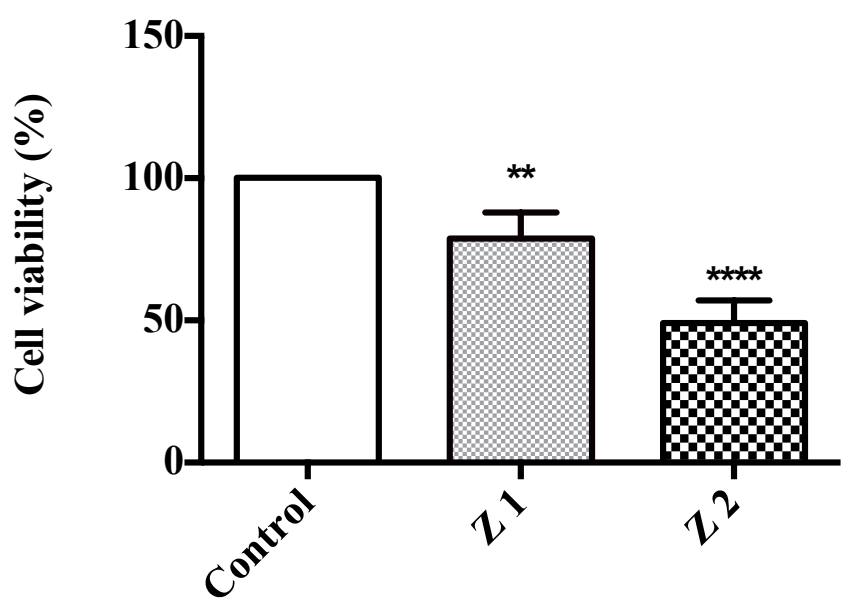

Figure 2. ZW effect on HCT-116 viability by MTT and Trypan blue assays. A) MTT results of HCT-116 cells treated with Z1 and Z2 compared to control untreated cells. B) Trypan blue cell count of HCT-116 cells treated with Z1 and Z2 compared to control untreated cells. The data represents the mean of three independent experiments $(\mathrm{n}=3 \pm \mathrm{SEM})$. Comparisons were made using one-way ANOVA followed by Bonferroni's test $(* * p=0.001-0.01, * * * * p$ $<0.0001)$. 
A) HCT-116

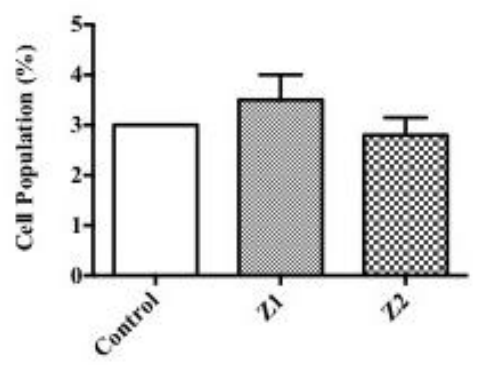

Early Apoptotic

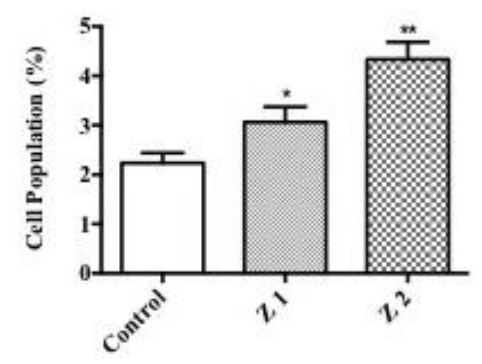

Late Apoptotic/Necrotic

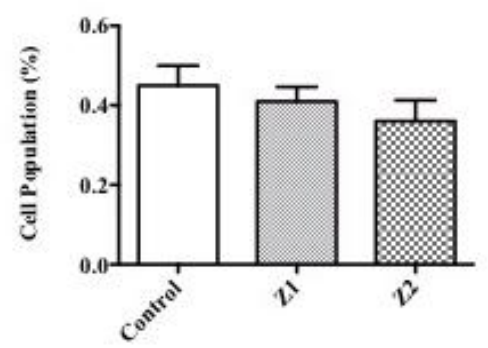

Necratic

B) HSF

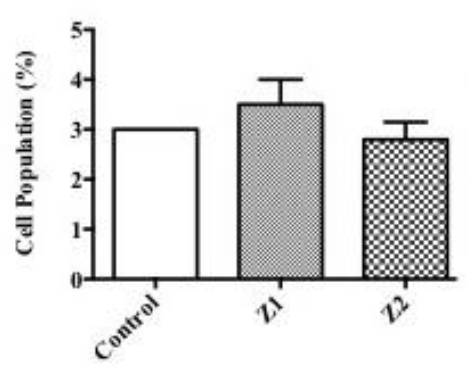

Early Apoptotic

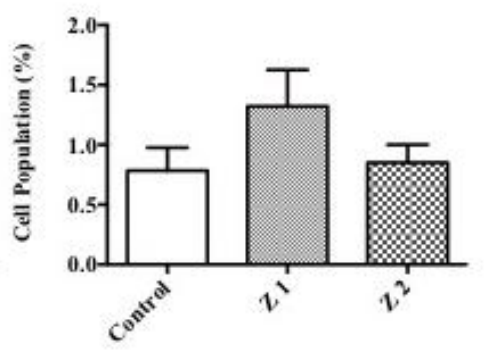

Late Apoptotic/Necrotic

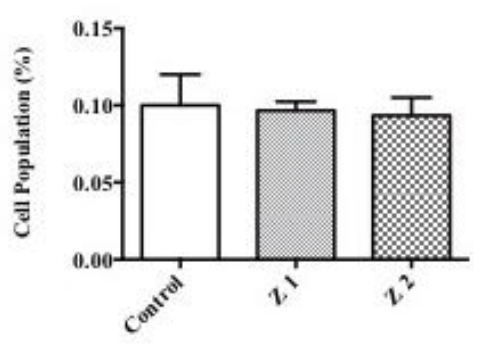

Necrotic

Figure 3. Determination of cell death mechanisms for HCT-116 and HSF cell lines after treatment with Z1 and Z2 for 24 hours. Represented values are the mean of three independent experiments performed by Flow cytometry ( $n=3 \pm$ SEM). Comparisons of means were made using one-way ANOVA followed by Bonferroni's test ( $* p=0.01-0.05, * * p=0.001-0.01)$. A) For HCT-116 cells, the percentage of early apoptosis was $3 \%, 3.5 \%$ and $2.8 \%$ in control vs. Z1 and Z2 respectively. In the late apoptotic stage, there was no significant difference between controls (2.6\%) and Z1 (2.6\%), while there was a significant increase (4.2\%) in Z2 compared to the control (**p $=0.001-0.01)$. Both treatments showed no significant effect in cell necrosis. B) For HSF cells, $\mathrm{Z} 1$ and $\mathrm{Z} 2$ showed no significant changes $(p>0.05)$ in all apoptotic stages and necrosis. The percentage of early apoptosis in HSF cells remained as low as $3 \%$, $3.5 \%$ and $2.8 \%$ for the control, $\mathrm{Z} 1$ and $\mathrm{Z} 2$, respectively. The proportion of death in the late apoptotic stage was $0.78 \%, 1.32 \%$ and $0.85 \%$ for the same treatments. The lowest percentage in necrotic stage was $0.1 \%, 0.9 \%$ and $0.093 \%$ for control, $\mathrm{Z} 1$ and $\mathrm{Z} 2$, respectively.

\section{A) HCT-116}

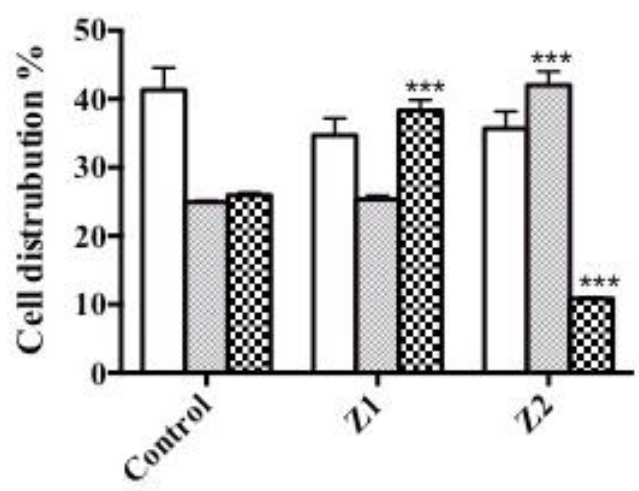

B) HSF

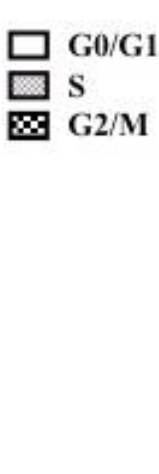

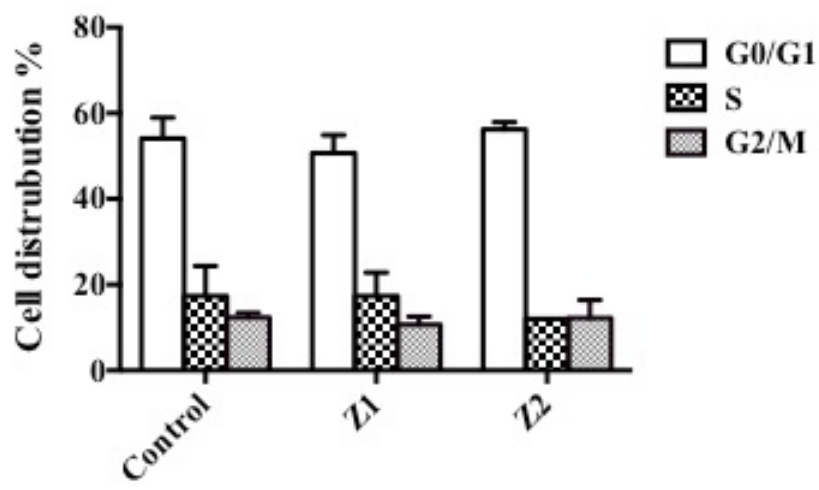

Figure 4. Cell cycle arrest in HCT-116 and HSF cells treated with $\mathrm{Z1}$ and $\mathrm{Z2}$ for $\mathbf{2 4}$ hours. Represented values are the means of three independent flow cytometry experiments $(\mathrm{n}=3 \pm \mathrm{SEM})$. Comparisons of means were made using one-way ANOVA followed by Bonferroni's test $(* * * p=0.0001-0.001)$. A) Effect of Z1 and Z2 on HCT-116 cell cycle distribution after 24 hours. The percentage of HCT-116 cells in the G0/G1 phase was 41\%, 34\% and 35\% for the control, Z1 and Z2, respectively. The percentage of cells in the S phase was $24 \%, 25 \%$ and $42 \%$ (*** $p=0.0001-0.001)$, while in the G2 phase; the percentage was $25 \%, 38 \%$ and $10 \%$ for the control, Z1 and Z2, respectively. B) Effect of Z1 and Z2 on HSF cell cycle distribution after 24 hours showed no significant effect $(p>0.05)$ in the G1, S and G2 phases compared to the control. The percentage of HSF cells in the G1 phase was $54.1 \%, 52.75 \%$ and $56.26 \%$ for the control, Z1 and Z2. The percentage of cells in the S phase was $17.33 \%, 17.33 \%$ and $12 \%$, while in the G2 phase; the percentage was $12.38 \%, 10.7 \%$ and $12.22 \%$ for the controls, $\mathrm{Z} 1$ and $\mathrm{Z} 2$, respectively. 


\subsection{Effect of Zamzam Treatments on Cell Cycle}

Fig 4A shows HCT-116 cell cycle phases after treatment with Z1 and Z2. Arrest in the G2/M phase was observed by noting a significant increase in the cell population treated with $\mathrm{Z} 1$, while the $\mathrm{S}$ phase arresting was observed in cells treated with Z2. The percentage of HCT-116 cells in the G0/G1 phase was $41 \%, 34 \%$ and $35 \%$ for the control, Z1 and Z2, respectively. The percentage of cells in the S phase was $24 \%, 25 \%$ and $42 \%(p=0.0001-0.001)$, whereas in the G2 phase, the percentage was $25 \%, 38 \%$ and $10 \%$ for the control, Z1 and Z2, respectively. In contrast to the HCT-116 cells, the same treatment of ZW on normal HSF showed no significant effect $(p>0.05)$ in the G1, S and G2 phases compared to the control as presented in Fig 4A \& 4B.

\subsection{Cellular and Mitochondrial ROS Measurement}

The calculated ROS formation intensity showed no significant difference in cellular ROS production in HCT-116 cells treated with Z1 or Z2 compared to the control (Fig 5A). ROS production intensity for $\mathrm{Z} 1$ and $\mathrm{Z} 2$ treated cells was $36 \mathrm{RFU}$ compared to the control, $35 \mathrm{RFU}$. Furthermore, the mtROS production (superoxide anion) was significantly observed with $\mathrm{Z} 1$ and $\mathrm{Z} 2$ compared to the control (in cells treated with Z1, the florescent intensity of mtROS formation was 9996 RFU while in cells treated with $\mathrm{Z} 2$, it was $14471 \mathrm{RFU}$ compared to $12425 \mathrm{RFU}$ in the control (Fig 5B).

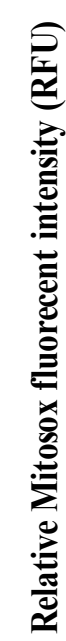

A

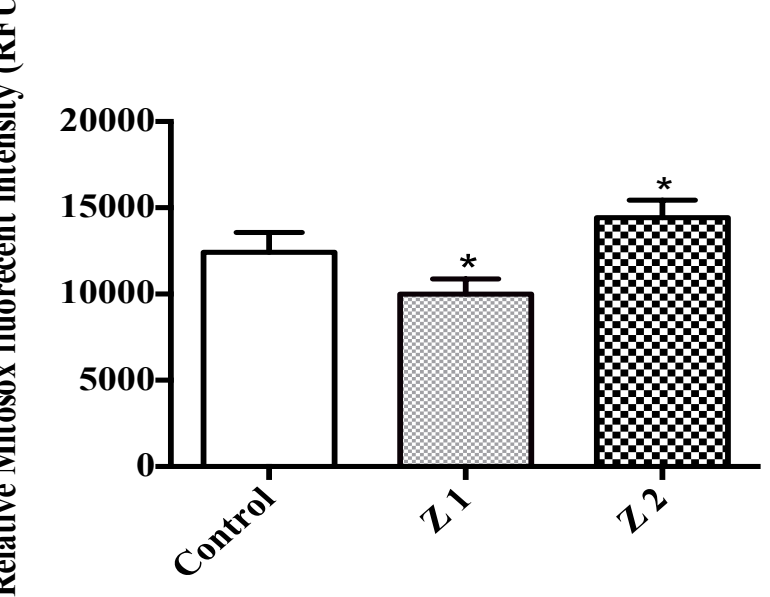

\section{Discussion}

Colorectal cancer (CRC) is one of the most prevalent types of cancer and a major cause of death globally [15]. To the best of our knowledge, this study is the first to investigate the cytotoxic and the apoptotic effects of $\mathrm{ZW}$ in human colon cancer cell line. Our results revealed that the incubation of HCT-116 cells with both $\mathrm{ZW}$ treatments resulted in morphological changes in HCT-116 cells and inhibited the growth and proliferation of cancer cells. Cytotoxic assays showed that the cell viability was significantly inhibited in HCT-116 cells for both ZW treatments, whereas the cell viability of HSF cells was not affected by both treatments. These results are in agreement with an in vivo study on rats that showed that the intake of ZW significantly diminished the size of colon tumor in rats [16]. Numerous researches have showed that minerals may play important roles in inhibiting the growth of cancer cells. Among these elements are calcium [17], magnesium [18], cadmium-zinc combinations, selenium [19], arsenate, lead [20,21], and lithium [11]. Furthermore, studies on colon cancer have demonstrated that arsenic trioxide and selenium are cytotoxic in human colon cancer cell lines [22,23]. Other studies showed that cadmium induced cytotoxicity in a concentration- and time-dependent manner in both colon cancer Caco-2 cells and normal human liver cell line HL-7702 [24].

Figure 5. Measurement of cellular and mitochondrial ROS production in HCT-116 cells treated with Z1 and Z2 for 24 hours. The data represent the mean of three independent experiments $(\mathrm{n}=3 \pm \mathrm{SEM})$. Comparisons of means were made using a one-way ANOVA followed by Bonferroni's test $(* p$ $=0.01-0.05$ ). A) HCT-116 cells treated with Z1 and Z2 for 24 hours. Cells were loaded with Mitosox stains and the fluorescence measured by flow cytometry to monitor mtROS formation. Results indicated a significant difference in the intensity for mtROS production in cells treated with Z1 and Z2 compared to control $\left({ }^{*} p=0.01-0.05\right)$. B) HCT-116 cells treated with Z1 and Z2 for 24 hours. Cells were loaded with CM- $\mathrm{H}_{2} \mathrm{DCFDA}$ and fluorescence DCF was measured by BioTek Fluorescence microplate reader to monitor ROS formation. Data showed no significant difference in the cellular ROS production in HCT-116 cells treated with Z1 or Z2 compared to the control. 
Calcium and magnesium are the major ions present in $\mathrm{ZW}$. Epidemiologic studies have pointed out the importance of calcium to magnesium ratio in reducing the risk of cancer [25]. Thus, ZW may be a beneficial source of the proper ratio of calcium to magnesium ions. Furthermore, the concentrations of toxic elements such as arsenate, lead and selenium are higher than any other water but still lower than the danger level of human consumption [8]. However, the difference between the therapeutic dose and toxicity is very small. Although it is not clear which component of $\mathrm{ZW}$ inhibits the growth of human colon cancer cells, it is presumed that the presence of small amounts of elements such as lithium and arsenic and the combined balanced mixture between other ions, as well as the alkaline nature of ZW could explain its healing properties [26].

Apoptosis, programmed cell death or cell suicide, is a mechanism by which most anticancer therapies kill tumor and cancer cells [27]. Our results revealed that both ZW treatments induced apoptosis in HCT-116 cells and did not show any effect on normal HSF cells. To confirm the induction of apoptosis by ZW, flow cytometric analysis using Annexin V/PI-stained cells was carried out. Cell cycle analysis showed that cells were arrested in the G2/M phase by the effect of $\mathrm{Z} 1$ treatment while $\mathrm{Z} 2$ treatment caused arresting of HCT-116 cells at $\mathrm{S}$ phase with significant reduction at $\mathrm{G} 2 / \mathrm{M}$ phase. Previous studies on elements proved that treating colon cancer cells with some elements inhibited the growth of colon cancer. A study showed that treatment of arsenic trioxide induced DNA damage in HT-29 colon cancer cells [22]. Another study reported that treating colon cancer cell lines with selenium induced G2/M cell cycle arrest [28]. It was also demonstrated that sodium selenite treatment accumulated HCT-116 cells at G2 phase, which was accompanied by the increasing expression of cyclin B1 [29]. In addition, it has been found that arresting at $\mathrm{G} 2 / \mathrm{M}$ phase in human tumor cell lines by arsenic trioxide is due to an increase of cyclin B level which is a regulatory protein involved in mitosis [30]. Moreover, arsenic trioxide arrested the cell cycle of HT-29 colon cancer cells at S phase [31]. Also, it was found that sodium selenite caused cell cycle arrest at S/G2 phase in both HCT116 and SW620 colon cell lines [23]. Arsenate induced cyclin D1 expression and $\mathrm{G}_{1}-\mathrm{S}$ transition in human keratinocytic HaCat cells [32]. In this study, it is assumed that the arresting effect of $\mathrm{Z} 1$ at G2/M phase of HCT-116 cells might be due to the increased cyclin B level by the effect of these elements that are found naturally in ZW, while the arresting effect of Z2 at S phase of the same cells might be due to the induction of cyclin D1 expression by the effect of both the alkaline $\mathrm{pH}$ and the balanced mixture of elements that are present naturally in $\mathrm{ZW}$. It was also reported that arsenic trioxide induced apoptosis, which was mediated through a mitochondria-dependent apoptotic signal pathway in human colorectal adenocarcinoma HT-29 cells [33]. In addition, it was also proved that selenium induced apoptosis via Bax-dependent mitochondrial pathway in both colon cancer cell lines [28]. Furthermore, studies on ERW showed that the treatment of ERW with GSH induced the mitochondrial apoptotic pathway in HL-60 cells [3]. All these findings are in agreement with our results in which apoptosis and not necrosis is induced.

Elevated rates of ROS have been detected in almost all cancers, where they promote tumor development and cancer cell progression. Accordingly, ROS level was investigated in HCT-116 cell line to assess the role of ROS in the induction of apoptosis after the exposure to $\mathrm{ZW}$ treatments. Our data demonstrated that mitochondrial ROS formations were induced only in Z2 treatment while Z1 treatment scavenged mtROS. The induction of mtROS by $\mathrm{Z} 2$ is may be due to mitochondrial dysfunction effect of $\mathrm{ZW}$ on cancer cells, whereas the scavenging of mtROS by $\mathrm{Z} 1$ treatment may be due to the activation of superoxide dismutase enzyme, which is induced by ZW. In contrast, the cellular ROS level of HCT-116 cells after ZW treatments was not changed when compared to the control. These findings are in agreement with those of Tasi and his colleagues [3] who reported the scavenging activity of ERW on the cellular ROS of HL-60 cells. Accordingly, our results showed that the generation of ROS seems to be the mechanism together with apoptosis that resulted in reduced cancer cell viability. The exact mechanism underlying the induction of apoptosis in HCT-116 cell line by ZW is not fully elucidated. The unique balanced combination of ions and the alkalinity of $\mathrm{ZW}$ are candidates for such effects.

\section{Conclusion}

All results throughout the study confirmed that $\mathrm{ZW}$ inhibits cell growth by apoptosis. ROS production may be an initiating event responsible for the mechanism of HCT-116 human colon cell death. Thus, ZW might be a promising natural cancer treatment. Further researches on different types of cancer cell lines are needed, in order to investigate the effect of $\mathrm{ZW}$ on other types of cancers.

\section{Acknowledgements}

The authors would like to express their deepest gratitude to The General Presidency of the Affairs of the Two Holy Mosques for providing ZW samples.

\section{REFERENCES}

[1] Jaganathan, S.K., Vellayappan, M.V., Narasimhan, G., Supriyanto, E., Dewi, D.E.O., Narayanan, A.L.T., Balaji, A., Subramanian, A.P., Yusof, M. Chemopreventive effect of apple and berry fruits against colon cancer. World Journal of Gastroenterology: WJG, 20(45), 17029-17036, 2014. 
[2] Alsanea, N., Abduljabbar, A.S., Alhomoud, S., Ashari, L.H., Hibbert. D., Bazarbashi. S. Colorectal cancer in Saudi Arabia: Incidence, survival, demographics and implications for national policies. Annals of Saudi Medicine, 35(3), 196-202, 2015.

[3] Tsai, C.F., Hsu, Y.W., Chen, W.K., Ho, Y,C., Lu, F.J. Enhanced induction of mitochondrial damage and apoptosis in human leukemia HL-60 cells due to electrolyzed-reduced water and glutathione. Bioscience, Biotechnology, and Biochemistry, 73(2), 280-287, 2009. DOI: 10.1271/bbb.80413.

[4] Ye, J., Li, Y., Hamasaki, T., Nakamichi, N., Komatsu, T., Kashiwagi, T., Toh, K. Inhibitory effect of electrolyzed reduced water on tumor angiogenesis. Biological \& Pharmaceutical Bulletin, 31(1),19-26, 2008.

[5] Lee, K.J., Park, S.K., Kim, J.W., Kim, G.Y., Ryang, Y.S., Kim, G.H., Kim, H.W. Anticancer effect of alkaline reduced water. Journal of International Society of Life Information Science (ISLIS), 22(2), 302-305, 2004.

[6] Khalid, N., Ahmad, A., Khalid, S., Ahmed, A., Irfan, M. Mineral composition and health functionality of zamzam water: A Review. International Journal of Food Properties, 17(3), 661-677, 2014. DOI: 10.1080/10942912.2012.660721.

[7] Naeem, N., Alsanussi, H., Almohandis, A. Multielemental and hydrochemical study of holy Zamzam water. Journal of the New England Water Works Association, 97(2), 159-169, 1983.

[8] Alfadul, S.M., Khan, M.A. Water quality of bottled water in the kingdom of Saudi Arabia: A comparative study with Riyadh municipal and Zamzam water. Journal of Environmental Science and Health, Part A, 46(13), 1519-1528, 2011.

[9] Shomar B. Zamzam water: Concentration of trace elements and other characteristics. Chemosphere, 86(6), 600-605, 2012.

[10] Wang, Y., Zhang, Y., Yang, L., Cai, B., Li, J., Zhou, Y., Lu, Y. Arsenic trioxide induces the apoptosis of human breast cancer MCF-7 cells through activation of caspase-3 and inhibition of HERG channels. Experimental and Therapeutic Medicine, 2(3), 481-486, 2011.

[11] Beyaert, R., Vanhaesebroeck, B., Suffys, P., Van Roy, F., Fiers, W. Lithium chloride potentiates tumor necrosis factor-mediated cytotoxicity in vitro and in vivo. Proceedings of the National Academy of Sciences, 86(23), 9494-9498, 1989.

[12] Griffin, A.C. The chemopreventive role of selenium in carcinogenesis. In Molecular Interrelations of Nutrition and Cancer. MS Arnott and J Van Eys, editors. River Press New York, 401-408, 1982.

[13] Estrella, V., Chen, T., Lloyd, M., Wojtkowiak, J., Cornnell, H.H., Ibrahim-Hashim, A., Bailey, K., Balagurunathan, Y., Rothberg, J.M., Sloane, B.F., Johnson. J. Acidity generated by the tumor microenvironment drives local invasion. Cancer Research, 73(5), 1524-1535, 2013.

[14] Robey, I.F., Baggett, B.K., Kirkpatrick, N.D., Roe, D.J., Dosescu, J., Sloane, B.F., Gillies, R.J. Bicarbonate increases tumor $\mathrm{pH}$ and inhibits spontaneous metastases. Cancer Research, 69(6), 2260-2268, 2009.
[15] Ferlay, J., Soerjomataram, I., Ervik, M., Dikshit, R., Eser, S., Mathers, C., Rebelo, M., Parkin, D.M., Forman, D., Bray, F.: GLOBOCAN 2012 v1.0, Cancer incidence and mortality worldwide: IARC CancerBase No. 11. International Agency for Research on Cancer, Lyon (France) 2013. Available from www:http://globocan.iarc.fr

[16] Ali, A.F.M., Cosemi, E., Kamel, S., Mohammed, S., Elhefnawy, M., Farid, L., Shaker, S. Oncolytic action of Zamzam water on azoxyonethone (AOM) induced colon tumors in rats. In Thirteenth International Water Technology Conference, IWTC, 13, 1521-1526, 2009.

[17] Lappe, J.M., Travers-Gustafson, D., Davies, K.M., Recker, R.R., Heaney, R.P. Vitamin D and calcium supplementation reduces cancer risk: results of a randomized trial. The American Journal of Clinical Nutrition, 85(6), 1586-1591, 2007.

[18] Wark, P.A., Lau, R., Norat, T., Kampman, E. Magnesium intake and colorectal tumor risk: A case-control study and meta-analysis. The American Journal of Clinical Nutrition, 96(3), 622-631, 2012.

[19] Remez, I., Rabkin, L., Veksler, H., Baumane, M. Cytotoxicity of cadmium, selenium, zinc and copper to mouse myeloma $\mathrm{Sp} 2 / 0$ cells as measured by the MTT Assay. Alternatives to Laboratory Animals: ATLA, 28(3), 473-476, 1999.

[20] Wang, Y., Zhang, Y., Yang, L., Cai, B., Li, J., Zhou, Y., Lu, Y. Arsenic trioxide induces the apoptosis of human breast cancer MCF-7 cells through activation of caspase- 3 and inhibition of HERG channels. Experimental and Therapeutic Medicine, 2(3), 481-486, 2011.

[21] Corbit, R., Ebbs, S., King, M.L., Murphy, L.L. The influence of lead and arsenite on the inhibition of human breast cancer MCF-7 cell proliferation by American ginseng root (Panax quinquefolius L.). Life Sciences, 78(12),1336-1340, 2006.

[22] Stevens, J.J., Graham, B., Walker, A.M., Tchounwou, P.B., Rogers, C. The effects of arsenic trioxide on DNA synthesis and genotoxicity in human colon cancer cells. International Journal of Environmental Research and Public Health, 7(5), 2018-2032, 2010.

[23] Fang, W., Han, A., Bi, X., Xiong, B., Yang, W. Tumor inhibition by sodium selenite is associated with activation of c - Jun NH2 - terminal kinase 1 and suppression of $\beta$ catenin signalling. International Journal of Cancer, 127(1), 32-42, 2010.

[24] Aziz, R., Rafiq, M.T., Yang, J., Liu, D., Lu, L., He, Z., Daud, M.K., Li, T., Yang, X. Impact assessment of cadmium toxicity and its bioavailability in human cell lines (Caco-2 and HL-7702). BioMed Research International, 2014.

[25] Dai, Q., Shrubsole, M.J., Ness, R.M., Schlundt, D., Cai, Q., Smalley, W.E., Li, M., Shyr, Y., Zheng, W. The relation of magnesium and calcium intakes and a genetic polymorphism in the magnesium transporter to colorectal neoplasia risk. The American Journal of Clinical Nutrition, 86(3),743-751, 2007.

[26] Al Meheithif, A., Elnour, A., Bamosa, A., Aleissa, K. Antioxidant effects of Zamzam water in normal rats and those under induced-oxidant stress. Journal of Medicinal Plants Research, 6(42), 5507-5512, 2012.

[27] Han, H., Long, H., Wang, H., Wang, J., Zhang, Y., Wang, Z. Progressive apoptotic cell death triggered by transient oxidative insult in $\mathrm{H} 9 \mathrm{c} 2$ rat ventricular cells: A novel pattern 
of apoptosis and the mechanisms. American Journal of Physiology-Heart and Circulatory Physiology, 286(6), H2169-H2182, 2004.

[28] Li, Z., Meng, J., Xu, T.J., Qin, X.Y., Zhou, X.D. Sodium selenite induces apoptosis in colon cancer cells via Bax-dependent mitochondrial pathway. European Review for Medical and Pharmacological Sciences, 17(16), 2166-71, 2013.

[29] Králová, V., Brigulová, K., Červinka, M., Rudolf, E. Antiproliferative and cytotoxic effects of sodium selenite in human colon cancer cells. Toxicology in Vitro, 23(8), 1497-1503, 2009.

[30] Ling, Y.H., Jiang, J.D., Holland, J.F., Perez-Soler, R. Arsenic trioxide produces polymerization of microtubules and mitotic arrest before apoptosis in human tumor cell lines. Molecular Pharmacology, 62(3), 529-538, 2002.
[31] Li, X., Ding, X., Adrian, T.E. Arsenic trioxide causes redistribution of cell cycle, caspase activation, and GADD expression in human colonic, breast, and pancreatic cancer cells. Cancer Investigation, 22(3), 389-400, 2004.

[32] Ouyang, W., Ma, Q., Li, J., Zhang, D., Liu, Z.G., Rustgi, A.K., Huang, C. Cyclin D1 induction through IкB kinase $\beta /$ nuclear factor- $\kappa \mathrm{B}$ pathway is responsible for arsenite-induced increased cell cycle G1-S phase transition in human keratinocytes. Cancer Research, 65(20), 9287-9293, 2005.

[33] Cha, Y., Park, D.W., Lee, C.H., Baek, S.H., Kim, S.Y., Kim, J.R., Kim, J.H. Arsenic trioxide induces apoptosis in human colorectal adenocarcinoma HT-29 cells through ROS. Cancer Research and Treatment, 38(1), 54-60, 2006. 